\title{
Hospital survey on patient safety culture in China
}

\author{
Yanli $\mathrm{Nie}^{1 \dagger}$, Xuanyue $\mathrm{MaO}^{1+}, \mathrm{Hao}_{\mathrm{Cui}}{ }^{2}$, Shenghong $\mathrm{He}^{3}$, Jing $\mathrm{Li}^{1}$ and Mingming Zhang ${ }^{1 *}$
}

\begin{abstract}
Background: Patient safety culture is an important measure in assessing the quality of health care. There is a growing recognition of the need to establish a culture of hospital focused on patient safety. This study explores the attitudes and perceptions of patient safety culture for health care workers in China by using a Hospital Survey on Patient Safety Culture (HSPSC) questionnaire and comparing it with the psychometric properties of an adapted translation of the HSPSC in Chinese hospitals with that of the US.

Method: We used the modified HSPSC questionnaire to measure 10 dimensions of patient safety culture from 32 hospitals in 15 cities all across China. The questionnaire included 1160 Chinese health-care workers who consisted of predominately internal physicians and nurses. We used SPSS 17.0 and Microsoft Excel 2007 to conduct the statistical analysis on survey data including descriptive statistics and validity and reliability of survey. All data was input and checked by two investigators independently.

Result: A total of 1500 questionnaires were distributed of which 1160 were responded validly (response rate 77\%). The positive response rate for each item ranged from 36\% to $89 \%$. The positive response rate on 5 dimensions (Teamwork Within Units, Organization Learning-Continuous Improvement, Communication Openness, Non-punitive Response and Teamwork Across Units) was higher than that of AHRQ data $(P<0.05)$. There was a statistical difference on the perception of patient safety culture in groups of different work units, positions and qualification levels. The internal consistency of the total survey was comparatively satisfied (Cronbach's $a=0.84$ ).

Conclusion: The results show that amongst the health care workers surveyed in China there was a positive attitude towards the patient safety culture within their organizations. The differences between China and the US in patient safety culture suggests that cultural uniqueness should be taken into consideration whenever safety culture measurement tools are applied in different culture settings.
\end{abstract}

Keywords: Patient Safety Culture, Hospital Questionnaire, Health Care Workers, Positive Response

\section{Background}

Patient safety is an important component of health care quality. Patient safety, including the measurement of patient safety culture is a top priority in developed countries today [1]. Research shows that safety and efficient care requires all the various elements of a health care system be well integrated and coordinated $[2,3]$.

Patient safety in the context of health care organizations was highlighted following the Institute of Medicine (IOM) report "To Error is Human: Building a Safer Health System" [4]. This report argued for a safety culture in which adverse events can be reported without

\footnotetext{
* Correspondence: mingming-zhang@163.com

${ }^{\dagger}$ Equal contributors

${ }^{1}$ Chinese Evidence-based Medicine Center, West China Hospital, Sichuan University, Chengdu 610041, PR China

Full list of author information is available at the end of the article
}

people being blamed, and that when mistakes occur that lessons are learned. Therefore, if hospitals want to improve patient safety, it is important to know more about the views of their staff in relation to the culture of patient safety.

Patient safety culture, also referred to patient safety climate, is the overall behavior of individuals and organizations, based on a common set of beliefs and values that are aimed at reducing the opportunities for patient harm [5,6]. Related research shows that when a positive patient safety culture exists, it will promote patient safety and help to improve patient safety standards, including the capacity and willingness to report minor errors, self-reporting errors, safety behaviors and safety audit rating [7-9].

To date, many developed countries have initiated the research into the role played by patient safety culture

\section{Biomed Central}


research. On a global basis, several international organizations promote the establishment of a culture of patient safety: the World Alliance for Patient Safety, the National Patient Safety Agency in the UK, the Agency for Healthcare Research and Quality in US and the Australia Commission of Safety and Quality in Australia. Related studies have also been conducted in Asian [10,11]. Most of the studies focus on evaluation of the psychometric properties of the HSPSC which has been translated in their own languages (Japan, Norway, Turkey, Netherlands, etc.) [11-14]. The studies from Japan and Norway showed the internal reliability of the subscale scores vary between factors, ranging from 0.46 to 0.88 , of which factor 'stuffing' had the lowest reliability ( 0.46 and 0.59 respectively) $[11,12]$. The internal consistency of some items in Arabic version of the HSOPSC was lower than that of the original items in the US study [15]. While there was some evidence suggested that the translation of the HSOPSC was acceptable in reliability and good construct validity $[11,14,16]$. The studies by Belgium, Turkey and Taiwan also used HSPSC to measure patient safety culture in their own countries[10,13,17].

In our research, we analyzed the attitudes and experiences of patient safety culture that Chinese health care workers had using a modified version of Hospital Survey of Patient Safety Culture (HSOPSC) of AHRQ. The purpose of this study was to measure the patient safety culture in China's hospitals and discuss some of the phenomena unique to China. We also compare some of the findings with existing data from benchmark scores using HSOPSC. Meanwhile, we intend to assess the quality of this investigative questionnaire. The findings of this study will provide health care organizations a better understanding about hospital culture and the extent to which patient safety attitudes are present in China.

\section{Methods}

\section{Questionnaire}

The questionnaire was translated and modified to suit the Chinese system. HSOPSC (the original U.S. English version 2010) was developed by Agency for Healthcare Research and Quality (AHRQ) in 2004 [18]. The original questionnaire of 2010 version was designed to assess 12 dimensions of health care with 42 items of patient safety culture. But two dimensions (Frequency of Events Reported and Handoffs and Transitions) with 13 items were omitted due to being sensitive, not adequately providing a response or semantically redundant or ambiguous because of translation [19]. Finally, 10 dimensions containing 29 items of hospital survey on patient safety culture were adopted (Table 1).

All items of HSOPSC questionnaire were developed based on the 5-point Likert response scale of agreement
("Strongly disagree" to "Strongly agree") or frequency ("Never" to "Always").

Two medical students translated the HSOPSC questionnaire into Chinese with a background in patient safety. The translation was double checked and reviewed by another two professors with background in patient safety, medicine and English.

\section{Sample}

This questionnaire was conducted in July to December in 2011 involving 1160 healthcare workers including physicians (surgical clinicians and internal clinicians) from each department and nurses representing different nursing units. Convenient sampling was used to select hospitals and participants including 32 hospitals in 15 cities across China. We included health care workers who are staff working in hospitals. We also included any kind of hospitals including specialized hospitals and traditional medicine hospitals.

Permission to conduct the investigation was granted by the hospitals or departments. The participants were informed of the purpose of the survey and voluntarily completed a paper copy of the questionnaire anonymously by the investigators who were present. The participants were encouraged to ask any questions if they did not understand the questionnaire. Questionnaires were regarded as invalid ones if there were inconsistent answers (e.g., an item with more than one answer). The questionnaires were valid if at least $70 \%$ of items were completed.

\section{Data analysis}

\section{Data collection}

After receiving the completed questionnaires, a preprocessing step was applied to remove incomplete or invalid data and based on the study by Hellings J [17]. The exclusion criteria were similar to the two studies $[17,20]$. They were as follows: 1) there was no entire section completed; 2) there was fewer than half items answered; or all the items answered the same. All data was entered by three researchers (Nie YL, Cui $\mathrm{H}$, and $\mathrm{SH} \mathrm{H}$ ) independently, and then were cross-checked mutually by Epidata (version, 3.02). In case of doubts or disagreement in some answers, we looked into the original questionnaires. Negatively worded items were reversed to ensure that positive answers indicated a higher score. Most of the items in the questionnaire used the Likert 5- point response scale of agreement (Strongly disagree to Strongly agree) or frequency (Never to Always),so the lowest three scoring (1-3) answers (Strongly disagree/Disagree/Neither Agree nor Disagree or Never/Rarely/Sometimes or Failing/Poor/ Acceptable), the highest two scoring (4-5) answers (Agree/ Strongly agree or Most of the time/Always or Very good/ Excellent) [21], as well as the highest two scoring answers 
Table 1 Demographic characteristic of respondents

\begin{tabular}{|c|c|c|c|c|}
\hline Characteristics & Physicians $(n=301)$ & Nurses $(n=722)$ & Others $(n=137)$ & Total $(n=1160)$ \\
\hline \multicolumn{5}{|l|}{ Working units } \\
\hline Internal medicine & $79(23.1)$ & 234(68.2) & $30(8.7)$ & $343\left(100^{a}\right)$ \\
\hline Surgery department & $106(27.4)$ & $250(64.8)$ & $30(7.8)$ & $386(100)$ \\
\hline Other units & 116(26.9) & 138(52.4) & $77(17.7)$ & $431(100)$ \\
\hline \multicolumn{5}{|l|}{ Years in hospital } \\
\hline$<1$ & $55(17.5)$ & 192(61.1) & $67(21.3)$ & $314(100)$ \\
\hline $1-5$ & 89(19.6) & $336(74.0)$ & $29(6.4)$ & 454(100) \\
\hline $6-10$ & $44(27.3)$ & 108(67.1) & $9(5.6)$ & 161(100) \\
\hline$\geq 11$ & 113(48.9) & $86(37.2)$ & $32(13.9)$ & $231(100)$ \\
\hline \multicolumn{5}{|l|}{ Years in department } \\
\hline$<1$ & $64(16.9)$ & $243(64.1)$ & 72(19.0) & $379(100)$ \\
\hline $1-5$ & 103(20.6) & $365(73.2)$ & $31(6.2)$ & 499(100) \\
\hline $6-10$ & $49(37.1)$ & $74(56.1)$ & $9(6.8)$ & 132(100) \\
\hline$\geq 11$ & $85(56.7)$ & $40(26.7)$ & 25(16.6) & 150(100) \\
\hline \multicolumn{5}{|c|}{ Hours working per week } \\
\hline$<20$ & $11(42.3)$ & $7(26.9)$ & $8(30.8)$ & $26(100)$ \\
\hline 20-39 & $31(15.7)$ & $129(65.5)$ & $37(18.8)$ & 197(100) \\
\hline $40-59$ & 136(18.3) & $531(71.5)$ & $76(10.2)$ & $743(100)$ \\
\hline$\geq 60$ & 123(63.4) & $55(28.4)$ & $14(8.2)$ & 194(100) \\
\hline \multicolumn{5}{|c|}{ Contact with patient directly } \\
\hline Yes, often & 294(26.8) & $702(64.1)$ & $99(9.0)$ & 1095(100) \\
\hline No & $6(9.5)$ & 19(30.2) & $38(60.3)$ & $63(100)$ \\
\hline
\end{tabular}

a Parenthesis represent percentage.

were perceived as positive response answers, and the lowest three scoring answers were deemed other response answer. We calculated the positive response rate to analyze the positive attitudes towards patient safety culture among different populations according to the formula by Grant MJ [22].

\section{Descriptive statistics}

We analyzed the demographic characteristics of the respondents with the Excel 2003. The number of positive response / positive response rates of all the items were also summarized. Positive response rate was used to evaluate the attitudes towards patient safety culture on different dimensions or items.

We used the Chi-Square test to analyze whether there was a statistical difference on health care workers in different sections, professionals and qualification levels towards patient safety culture. We used the KruskalWallis test to infer if there was a statistical difference on Patient Safety Grade and Number of Events Reported in Chinese hospitals compared with that of US hospitals, with the significant level of $\mathrm{P}=0.05$ [21].

We calculated the reliability and exploration factor analysis to evaluate the quality of the questionnaire.
Internal consistency value (Gronbach's $\alpha \geq 0.70$ ) for newly developed scales was recommended. Structure validity was explored using principal component factor analysis by Kaiser-Meyer-Olkin Measure of Sampling Adequacy $(\mathrm{KMO}>0.7)$ and by Bartlett's Test of Sphericity $P<0.05$.

\section{Ethic}

The study was conducted according to the principle of Helsinki Declaration. The protocol has been reviewed and approved by the Chinese Ethic Committee of Registering Clinical Trials (ChiECRCT-2011021).

\section{Results}

\section{Sample and response statistics}

A total of 1500 questionnaires were distributed of which 1160 were responded validly (response rate $77 \%$ ). Seven hundred and twenty two (66\%) of the respondents were nurses, 386 (33\%) were surgical clinicians and 343 (30\%) were internal medicine clinicians. The majority of respondents (94\%) usually dealt with patients directly (Table 1).

Table 2 showed that the positive response rate for the 10 patient safety culture dimensions ranged from $45 \%$ to $88 \%$, the mean positive response rate was $65 \%$. The lowest positive response rate of dimension was Staffing 
Table 2 Positive response rate of each item and Cronbach's a for dimensions

Dimension/items(internal consistency reliability coefficient)

1.Teamwork Within Units (Cranach's $a=0.72$ )

\section{US}

$80 \%$

$86 \%$

$86 \%$

$78 \%$

$69 \%$

$75 \%$

$76 \%$

$74 \%$

$76 \%$

$72 \%$

$84 \%$

$69 \%$

$72 \%$

$81 \%$

$75 \%$

$61 \%$

$66 \%$

$62 \%$

$64 \%$

$72 \%$

$64 \%$

$56 \%$

$65 \%$

$72 \%$

$62 \%$

$75 \%$

$47 \%$

$63 \%$

$44 \%$

$50 \%$

$46 \%$

$35 \%$

$58 \%$

$60 \%$

$56 \%$

$56 \%$

$51 \%$

$44 \%$

$45 \%$
China

$84 \%$

$87 \%$

$$
87 \%
$$

$80 \%$

$$
81 \%
$$$$
63 \%
$$

$76 \%$

$36 \%$

$78 \%$

$88 \%$

$87 \%$

$89 \%$

$69 \%$

$71 \%$

$70 \%$

$65 \%$

$55 \%$

$61 \%$

$37 \%$

$65 \%$

$50 \%$

$54 \%$

$64 \%$

$53 \%$

$65 \%$

$51 \%$

$80 \%$

$64 \%$

$60 \%$

$53 \%$

$67 \%$

$60 \%$

$66 \%$

$66 \%$

$45 \%$

$42 \%$

$38 \%$

$37 \%$

$61 \%$

A14. We work in "crisis mode" trying to do too much, too quickly.

(45\%), while the highest positive response rate of dimension was Organization Learning-Continuous Improvement (88\%). There were three dimensions of which positive response rate were less than $60 \%$ such as Overall Perception of Patient Safety (55\%), Feedback E Communication About
Error (50\%), and Staffing (45\%). The positive response rate for the rest of the items ranged from $36 \%$ to $89 \%$. The highest positive response rate of the items was After we make changes to improve patient safety, we evaluate their effectiveness (89\%), while the lowest positive response rate 
of the item was Whenever pressure builds up, my supervisor/manager wants us to work faster, even if it means taking shortcuts (36\%).

However, Hospital Survey on Patient Safety Culture2012 User Comparative Database Report [21] showed that the average positive response rate of 12 dimensions ranged from $35 \%$ to $86 \%$, the overall average positive response rate for dimensions was $63 \%$. The lowest positive response rate of item was Staff worry that mistakes they make are kept in their personal file (35\%) and the highest positive response rate items were People support one another in this facility (86\%) and When a lot of work needs to be done quickly, we work together as a team to get the work done (86\%). There were 11 items of which the positive response rate were less than 60\%, see details in Table 2.

There were some differences between the adapted Chinese HSPSC with that of original US HSPSC, so only the same items were compared to explore the differences of perceptions towards patient safety culture between the two countries. The results showed that there was a significant difference on 10 items $(\mathrm{P}<0.05)$, of which the positive response rate on 10 items in China was higher than that of the US. These dimensions were (1) Teamwork Within Units, Organization (2) Learning-Continuous Improvement, (3) Communication Openness, (4) Nonpunitive response and (5) Teamwork Across Units. However, there was a significant difference on 10 items $(\mathrm{P}<0.05)$, which of the positive response rate on 10 items in China was lower than that of the US, these dimensions were (1) Supervisor/Manager Expectations E Actions Promoting (2) Patient Safety, Management Support for Patient Safety, (3) Overall Perception of Patient safety, (3) Feedback $\mathcal{E}$ Communication About Errors and (4) Staffing (Table 2).

\section{Comparative results}

The results showed that there was a significant difference on eight dimensions between physicians and nurses (i.e. Teamwork Within Units, Organization Learning-Continuous Improvement, Management Support for Patient Safety, Feedback \& Communication About Errors, Overall Perception of Patient Safety, Communication Openness, Non-punitive response to Errors and Staffing, $\mathrm{P}<0.05)$. The positive response rate of two items of nurses was lower than that of physicians (It is just by chance that more serious mistakes don't happen around here and Staff will freely speak up if they see something that may negatively affect patient care, $\mathrm{P}<0.05)$. The positive response rate of other items of nurses was higher than that of physicians (Table 3 ).

Incidence of patient safety events was closely related to the qualification level of physicians. Our result showed that there was a significant difference in the positive response rate on seven dimensions (i.e. Teamwork Within Units, Management Support for Patient Safety, Teamwork
Across Units, Feedback E Communication About Errors, Overall Perception of Patient Safety, Communication Openness and Non-punitive Response to Errors, $\mathrm{P}<0.05$ ) for residents, attending physicians, deputy directors and chief physicians. Furthermore, the positive response rate of physicians with high qualification (chief physicians) on two dimensions (Overall Perception of Patient safety and Feedback \& Communication About Errors) was higher than those having a low qualification level (residents), while the positive response rate of healthcare professionals with a high qualification level on five dimensions (Teamwork Within Units, Management Support for Patient Safety, Communication Openness, Teamwork Across Units and Non-punitive Response to Errors) was lower than that of those who have low qualification levels (Table 4).

\section{Patient safety grade/number of events reported both in China and the US}

According to the Hospital Survey on Patient Safety Culture-2012 User Comparative Database Report, the positive response rate on Patient Safety Grade in the US was $75 \%$, while it was $73 \%$ in China. There was no significant difference between the two groups $(P=0.223$, see Table 2). However, there were significant differences on all the answers of Patient Safety Grade and the Number of Events Reported between the two countries (Table 5).

\section{Reliability and validity}

The reliability of the 10 dimensions was shown in Table 2. For the 10 dimensions, the internal consistency (Cronbach's $\alpha$ ) ranged from 0.40 to 0.64 , and the Cronbach's $\alpha$ of the total scale in our study was 0.84 which was lower than that of the original factor scale in the US.

Table 6 displayed the inter-correlations of the $10 \mathrm{di}$ mensions, and correlations between the scale scores were also calculated. Management Support for Patient Safety and Overall Perception of Patient Safety $(\mathrm{r}=0.77)$ are most correlated, while Teamwork Within Units and Communication Openness $(\mathrm{r}=0.10)$ were least correlated. The highest correlation was 0.65 between Feedback \& Communication about Errors and the scale $(\mathrm{r}=0.65)$, and the correlation between each dimension and the total scale is significantly different (Table 6).

Bartlett's test of the 29 items on patient safety culture demonstrated a sufficient inter-item correlation: $\mathrm{X}^{2}=2163.578, \mathrm{df}=1159, \mathrm{P}<0.01$. Furthermore, the Kaiser-Meyer-Olkin measure of sampling adequacy was satisfactory, with a value of 0.829 . Explorative factor analysis was performed using principal component analysis with varimax rotation. Using the explorative factor analysis drew eight factors. The factors cumulatively 
Table 3 The comparison of attitudes of nurse versus physicians on patient safety culture

\begin{tabular}{|c|c|c|c|c|c|c|}
\hline \multirow[t]{2}{*}{ Items } & \multicolumn{2}{|c|}{ Nurse } & \multicolumn{2}{|c|}{ Physicians } & \multirow[t]{2}{*}{$\mathrm{x}^{2}$} & \multirow[t]{2}{*}{$\mathbf{p}$} \\
\hline & NPR & NOR & NPR & NOR & & \\
\hline A1. People support one another in this facility & 624 & 97 & 270 & 31 & 1.93 & 0.17 \\
\hline A3. When a lot of work needs to be done quickly, we work together as a team to get the work done & 647 & 75 & 250 & 51 & 8.45 & 0.01 \\
\hline A4. In facility, people treat each other with respect & 692 & 29 & 267 & 34 & 19.42 & 0.01 \\
\hline A11. When one area in this unit gets really busy, others help out & 607 & 115 & 231 & 70 & 7.7 & 0.01 \\
\hline B2. Manager says a good word when he/she sees a job done according to established & 540 & 182 & 242 & 59 & 3.78 & 0.06 \\
\hline $\begin{array}{l}\text { B3. Whenever pressure builds up, my supervisor/manager wants us to work faster, even if it means taking } \\
\text { shortcuts }\end{array}$ & 458 & 264 & 203 & 98 & 1.49 & 0.22 \\
\hline B4. My supervisor/manager overlooks patient safety problems that happen over and over & 559 & 163 & 243 & 58 & 1.37 & 0.24 \\
\hline A6. We are actively doing things to improve patient safety. & 646 & 75 & 250 & 51 & 8.41 & 0.01 \\
\hline A13. After we make changes to improve patient safety, we evaluate their effectiveness. & 654 & 68 & 258 & 43 & 5.2 & 0.02 \\
\hline F1. Hospital management provides a work climate that promotes patient safety. & 536 & 186 & 193 & 108 & 10.62 & 0.01 \\
\hline F8. The actions of hospital management show that patient safety is a top priority. & 590 & 132 & 233 & 68 & 2.51 & 0.11 \\
\hline F9. Hospital management seems interested in patient safety only after an adverse event happens & 478 & 244 & 193 & 108 & 0.41 & 0.52 \\
\hline A10. It is just by chance that more serious mistakes don't happen around here. & 556 & 166 & 271 & 30 & 23.27 & 0.01 \\
\hline A17. We had patient safety problems in this unit. & 446 & 276 & 195 & 106 & 0.82 & 0.36 \\
\hline A18. Our procedures and systems are good at preventing errors from happening. & 497 & 225 & 174 & 127 & 11.45 & 0.01 \\
\hline C1. We are given feedback about changes put into place based on event reports. & 385 & 337 & 169 & 132 & 0.68 & 0.41 \\
\hline C3. We are informed about errors that happen in this unit. & 490 & 232 & 163 & 139 & 17.31 & 0.01 \\
\hline C5. In this unit, we discuss ways to prevent errors from happening again. & 419 & 303 & 136 & 165 & 14.13 & 0.01 \\
\hline C2. Staff will freely speak up if they see something that may negatively affect patient care. & 347 & 375 & 175 & 126 & 8.63 & 0.01 \\
\hline C4. Staffs are afraid to ask questions when something does not seem right. & 596 & 126 & 224 & 77 & 8.83 & 0.01 \\
\hline C6. Staffs feel free to question the decisions or actions of those with more authority. & 593 & 129 & 232 & 69 & 3.48 & 0.06 \\
\hline A8. Staff feel like their mistakes are held against them. & 646 & 75 & 237 & 64 & 21.74 & 0.01 \\
\hline A12. When an event is reported, it feels like the person is being written up, not the problem. & 615 & 107 & 250 & 51 & 0.73 & 0.39 \\
\hline A16. Staff worry that mistakes they make are kept in their personnel file. & 644 & 75 & 273 & 28 & 0.29 & 0.59 \\
\hline F4. There is good cooperation among hospital units that need to work together. & 480 & 242 & 184 & 117 & 2.67 & 0.10 \\
\hline A2. We have enough staff to handle the workload. & 457 & 265 & 146 & 155 & 19.21 & 0.01 \\
\hline A5. Staffs in this unit work longer hours than is best for patient care. & 450 & 272 & 182 & 118 & 0.25 & 0.81 \\
\hline A7. We use more agency/temporary staff than is best for patient care. & 489 & 233 & 171 & 130 & 11.06 & 0.01 \\
\hline A14. We work in "crisis mode" trying to do too much, too quickly. & 606 & 116 & 250 & 51 & 0.12 & 0.79 \\
\hline
\end{tabular}

Legend:NPR, Number of positive response answers; NOR, Number of other response answers.

explained $60 \%$ of the variance in the survey and the result was acceptable.

Table 7 demonstrated the factor loadings for each item (all loadings $>0.40$ ). Factor one loadings on five dimensions (Teamwork Within Units, Management Support for Patient Safety, Overall Perceptions of Patient Safety, Communication Openness and Teamwork Across Units), and factor two and six loading on Supervisor/ManagerExpectations \& Actions Promoting Patient Safety (Table 7).

\section{Discussion}

Safety culture originated from high reliability organizations (HROs) in the last several decades, which has gained much attention in health care fields to promote patient safety recently both in individual work units or hospitals [23]. This has improved since the Hospital Survey on Patient Safety Scale (HSPSC) was introduced by the Agency for Healthcare Research and Quality (AHRQ). The HSPSC survey has been translated into 24 languages in 45 countries to measure patient safety culture in their own healthcare organizations $[18,21]$.

In our study, we used revised HSPSC to measure patient safety culture in China. A total of 1,500 of questionnaires were distributed to 32 hospitals in 15 cities across China of which 1,160 respondents were eligible. The response rate was $77 \%$, which was similar to the study implemented in Taiwan [10]. The overall positive response rate for 29 items was acceptable which was 
Table 4 The attitudes of physicians with different levels on patient safety culture

Items
A1. People support one another in this facility
A3. When a lot of work needs to be done quickly, we work together as a team to
get the work done
A4. In facility, people treat each other with respect
A11. When one area in this unit gets really busy, others help out
B2. Manager says a good word when he/she sees a job done according to
established

B3. Whenever pressure builds up, my supervisor/manager wants us to work faster, even if it means taking shortcuts

B4. My supervisor/manager overlooks patient safety problems that happen over and $\begin{array}{llllllllll}95 & 13 & 66 & 19 & 49 & 15 & 33 & 11 & 5.78 & 0.12\end{array}$ over

A6. We are actively doing things to improve patient safety.

A13. After we make changes to improve patient safety, we evaluate their effectiveness.

F1. Hospital management provides a work climate that promotes patient safety.

F8. The actions of hospital management show that patient safety is a top priority.

F9. Hospital management seems interested in patient safety only after an adverse event happens

A10. It is just by chance that more serious mistakes don't happen around here.

A17. We had patient safety problems in this unit.

A18. Our procedures and systems are good at preventing errors from happening.

C1. We are given feedback about changes put into place based on event reports.

C3. We are informed about errors that happen in this unit.

C5. In this unit, we discuss ways to prevent errors from happening again.

C2. Staff will freely speak up if they see something that may negatively affect patient care.

C4. Staffs are afraid to ask questions when something does not seem right.

\begin{tabular}{|c|c|c|c|c|c|c|c|c|c|}
\hline \multicolumn{2}{|c|}{ Residents } & \multicolumn{2}{|c|}{$\begin{array}{l}\text { Attending } \\
\text { physicians }\end{array}$} & \multicolumn{2}{|c|}{$\begin{array}{l}\text { Deputy } \\
\text { directors }\end{array}$} & \multicolumn{2}{|c|}{$\begin{array}{l}\text { Chief } \\
\text { physicians }\end{array}$} & \multirow[t]{2}{*}{$x^{2}$} & \multirow[t]{2}{*}{$P$} \\
\hline NPR & NOR & NPR & NOR & NPR & NOR & NPR & NOR & & \\
\hline & 10 & 77 & 8 & 57 & 7 & 38 & 6 & 0.76 & 0.86 \\
\hline & 10 & 69 & 16 & 44 & 20 & 39 & 5 & 14.98 & 0.01 \\
\hline
\end{tabular}

$\begin{array}{llllllllll}99 & 9 & 72 & 13 & 58 & 6 & 38 & 6 & 2.77 & 0.43\end{array}$

$\begin{array}{llllllllll}88 & 20 & 60 & 25 & 49 & 15 & 34 & 10 & 3.16 & 0.37\end{array}$

$\begin{array}{llllllllll}95 & 13 & 67 & 18 & 47 & 17 & 33 & 11 & 6.81 & 0.08\end{array}$

$\begin{array}{llllllllll}66 & 42 & 56 & 29 & 47 & 17 & 34 & 10 & 5.03 & 0.17\end{array}$

$\begin{array}{llllllllll}95 & 13 & 66 & 19 & 49 & 15 & 33 & 11 & 5.78 & 0.12\end{array}$

$\begin{array}{llllllllll}93 & 15 & 70 & 15 & 49 & 15 & 38 & 6 & 3.00 & 0.39\end{array}$

$\begin{array}{llllllllll}95 & 13 & 69 & 16 & 55 & 9 & 39 & 5 & 2.18 & 0.54\end{array}$

$\begin{array}{llllllllll}84 & 24 & 42 & 43 & 40 & 24 & 27 & 17 & 16.91 & 0.01\end{array}$

$\begin{array}{llllllllll}90 & 18 & 61 & 24 & 46 & 18 & 36 & 8 & 5.31 & 0.15\end{array}$

$\begin{array}{llllllllll}77 & 31 & 51 & 34 & 38 & 26 & 27 & 17 & 3.80 & 0.28\end{array}$

$\begin{array}{llllllllll}96 & 12 & 77 & 8 & 57 & 7 & 41 & 3 & 0.74 & 0.86\end{array}$

$\begin{array}{llllllllll}50 & 58 & 64 & 21 & 45 & 19 & 36 & 8 & 26.66 & 0.01\end{array}$

$\begin{array}{llllllllll}76 & 32 & 40 & 45 & 38 & 26 & 20 & 24 & 13.79 & 0.01\end{array}$

$\begin{array}{llllllllll}69 & 39 & 46 & 39 & 32 & 32 & 22 & 22 & 4.41 & 0.22\end{array}$

$\begin{array}{llllllllll}64 & 44 & 45 & 40 & 30 & 34 & 24 & 20 & 2.54 & 0.47\end{array}$

$\begin{array}{llllllllll}64 & 44 & 45 & 40 & 30 & 34 & 24 & 20 & 2.54 & 0.47 \\ 47 & 61 & 40 & 45 & 46 & 18 & 32 & 12 & 20.78 & 0.01\end{array}$

$\begin{array}{llllllllll}76 & 32 & 50 & 35 & 29 & 35 & 20 & 24 & 13.84 & 0.01\end{array}$

C6. Staffs feel free to question the decisions or actions of those with more authority.

A8. Staff feel like their mistakes are held against them.

A12. When an event is reported, it feels like the person is being written up, not the problem.

A16. Staff worry that mistakes they make are kept in their personnel file.

F4. There is good cooperation among hospital units that need to work together.

A2. We have enough staff to handle the workload.

A5. Staffs in this unit work longer hours than is best for patient care.

A7. We use more agency/temporary staff than is best for patient care.

A14. We work in "crisis mode" trying to do too much, too quickly.

$\begin{array}{llllllllll}83 & 25 & 64 & 21 & 47 & 17 & 30 & 14 & 1.30 & 0.73 \\ 78 & 30 & 68 & 17 & 55 & 9 & 31 & 13 & 5.77 & 0.12 \\ 92 & 16 & 66 & 19 & 45 & 19 & 34 & 10 & 5.49 & 0.14 \\ 99 & 9 & 69 & 16 & 47 & 17 & 35 & 9 & 10.46 & 0.02\end{array}$

\begin{tabular}{llllllllll}
99 & 9 & 77 & 8 & 57 & 7 & 40 & 4 & 0.33 & 0.96 \\
85 & 23 & 44 & 41 & 32 & 32 & 23 & 21 & 21.89 & 0.01 \\
65 & 43 & 36 & 49 & 35 & 29 & 19 & 25 & 7.56 & 0.06 \\
64 & 43 & 49 & 36 & 38 & 26 & 31 & 13 & 2.16 & 0.54 \\
66 & 42 & 45 & 40 & 40 & 24 & 20 & 24 & 4.47 & 0.21 \\
90 & 18 & 67 & 18 & 53 & 11 & 40 & 4 & 3.01 & 0.39 \\
\hline
\end{tabular}

Legend:NPR, Number of positive response answers; NOR, Number of other response answers.

higher than the other two studies conducted in Taiwan by Chen and the mainland of China by Zhu $[10,19]$. Comparing with the two studies by Chen 2010 and by Zhu 2012, we found that the participants surveyed by the study in Taiwan was a light different from our study regarding to the included participants that $29 \%$ of the respondents were physicians, $60 \%$ were nurses, and $10 \%$ were administrators, while there was no administrators included in our study. There was also a time difference between the two studies. The research in Taiwan was conducted from January 2006 to February 2008 which was three years earlier than that of our study. The results showed the dimension that received the highest positive rate was 'Teamwork within units', and the lowest percentage of positive responses was 'Staffing' which is also similar to our study. There was also a difference 
Table $\mathbf{5}$ The comparisons of patient safety grade between different professionals

\begin{tabular}{llllll}
\hline Patient safety grade & Physicians (\%) & Nurses (\%) & Others (\%) & Overall (\%) & Benchmark (\%) \\
\hline Excellent & $55^{\mathrm{a}}(18)$ & $122(17)$ & $23(12)$ & 17 & 30 \\
Very good & $157(52)$ & $420(58)$ & $75(12)$ & 56 & 45 \\
Acceptable & $79(26)$ & $163(23)$ & $35(13)$ & 24 & 20 \\
Pool & $10(3)$ & $15(2)$ & $4(14)$ & 3 & 4 \\
Failing & $0(0)$ & $2(0.3)$ & $0(0)$ & 0.2 & 1 \\
\hline
\end{tabular}

${ }^{a}$ number of the respondents.

from the study by Zhu 2012 [19] from our study regarding to the purpose that the study by Zhu 2012 focused on assessing the appropriateness of existing safety culture questionnaires used in the USA and Japan for Chinese respondents. In this study, the authors identified new items and domains suitable to Chinese hospitals. Eight new items and three additional dimensions were identified addressing staff training, mentoring of new hires, compliance with rules and procedures etc. The results from both studies recognized that adequate staff is crucial for patient safety and is one of the biggest challenges which is consistent with the results from our study.

The result showed that the positive response rate for each item ranged from $36 \%$ to $89 \%$. The dimensions that received the highest positive response rate were Teamwork Within Units, while the dimensions for the lowest positive response rate was Staffing. Moreover, the positive response rate of five dimensions: Teamwork Within Units, Organization Learning-continuous Improvement, Communication Openness, Non-punitive Response to Errors and Teamwork Across Units in Chinese hospitals (84\%, 88\%, 65\%, 60\%, and 66\%, respectively) was higher than that of US hospitals $(80 \%, 75 \%, 72 \%, 62 \%, 44 \%$ and $58 \%$, respectively). The results may imply one of the core values of Chinese culture is prioritizing harmony. The Chinese are warm and willing to help others and place relatively more emphasis on cooperation and learning [24-26]. The positive response rate of four dimensions of Staffing, Feedback \& Communication About Errors, overall Perception of Patient Safety and Management Support for Patient Safety (45\%, 50\%, 55\% and $69 \%$, respectively) was lower than that of US study (56\%, 64\% 66\% and 72\%, respectively). The results suggested many health care workers in Chinese setting shy away from discussing or reporting adverse events, asking questions or challenging those with more authority even when they disagree [19]. The lowest percentage of positive response rate was "Staffing", which means that most of the respondents felt that staff allocation is not adequate to handle patient safety related workload, especially in some comprehensive hospitals where there is a greater ratio of patients to staff. A similar finding was reported by Hellings and the study conducted in Taiwan and China $[10,17,19]$.

The perception of patient safety culture was different in different environments, for example working units, professionals and so on [12]. The results showed that the positive response numbers of nurses regarding patient safety culture was higher than that of physicians in our study. Nurses spent more time in contacting and communicating with patients [22,27], so they had more opportunity to deal with patient safety issues. In China there is a strict professional training about patient safety in clinical practice for nurses which may account for this higher positive response. In addition, our study found that the positive response rate of physicians with a high

Table 6 Correlation with the total scale and inter-correlations of the 10 dimensions

\begin{tabular}{|c|c|c|c|c|c|c|c|c|c|c|c|}
\hline Dimensions & 1 & 2 & 3 & 4 & 5 & 6 & 7 & 8 & 9 & 10 & Total \\
\hline 1. Teamwork Within Units & 1.00 & 0.63 & 0.37 & 0.33 & 0.31 & 0.28 & 0.10 & 0.05 & 0.24 & 0.27 & $0.52^{*}$ \\
\hline 2. Supervisor/Manager Expectations \& Actions Promoting Patient Safety & & 1.00 & 0.32 & 0.44 & 0.55 & 0.48 & 0.19 & 0.13 & 0.42 & 0.43 & $0.64^{*}$ \\
\hline 3. Organizational Learning_Continuous Improvement & & & 1.00 & 0.70 & 0.39 & 0.31 & 0.07 & -0.04 & 0.20 & 0.32 & $0.41^{*}$ \\
\hline 4. Management Support for Patient Safety & & & & 1.00 & 0.77 & 0.47 & 0.16 & 0.08 & 0.40 & 0.46 & $0.53^{*}$ \\
\hline 5. Overall Perceptions of Patient Safety & & & & & 1.00 & 0.72 & 0.25 & 0.15 & 0.47 & 0.53 & $0.63^{*}$ \\
\hline 6. Feedback \& Communication About Error & & & & & & & & 0.18 & 0.42 & 0.43 & $0.65^{*}$ \\
\hline 7. Communication Openness & & & & & & & & 0.67 & 0.26 & 0.14 & $0.48^{*}$ \\
\hline 8. Nonpunitive Response to Errors & & & & & & & & 1.00 & 0.57 & 0.09 & $0.40^{*}$ \\
\hline 9. Teamwork Across Units & & & & & & & & & 1.00 & 0.56 & $0.59^{*}$ \\
\hline 10. Staffing & & & & & & & & & & 1.00 & $0.60^{*}$ \\
\hline
\end{tabular}

"All correlations are significant at $\mathrm{P}<0.001$. 
Table 7 Factors loading in each item

\begin{tabular}{|c|c|c|c|c|c|c|c|c|}
\hline Items & 1 & 2 & 3 & 4 & 5 & 6 & 7 & 8 \\
\hline A1. People support one another in this facility & 0.57 & & & & & & & \\
\hline $\begin{array}{l}\text { A3. When a lot of work needs to be done quickly, we work together as a team to get the work } \\
\text { done }\end{array}$ & 0.64 & & & & & & & \\
\hline A4. In facility, people treat each other with respect & 0.50 & & & & & & & \\
\hline A11. When one area in this unit gets really busy, others help out & 0.66 & & & & & & & \\
\hline B2. Manager says a good word when he/she sees a job done according to established & & 0.63 & & & & & & \\
\hline $\begin{array}{l}\text { B3. Whenever pressure builds up, my supervisor/manager wants us to work faster, even if it means } \\
\text { taking shortcuts }\end{array}$ & & 0.50 & & & & 0.44 & & \\
\hline B4. My supervisor/manager overlooks patient safety problems that happen over and over & & & & & & 0.58 & & \\
\hline A6. We are actively doing things to improve patient safety. & & & & & & & 0.47 & \\
\hline A13. After we make changes to improve patient safety, we evaluate their effectiveness. & & & & & & & 0.58 & \\
\hline F1. Hospital management provides a work climate that promotes patient safety. & 0.65 & & & & & & & \\
\hline F8. The actions of hospital management show that patient safety is a top priority. & 0.70 & & & & & & & \\
\hline F9. Hospital management seems interested in patient safety only after an adverse event happens & 0.56 & & & & & & & \\
\hline A10. It is just by chance that more serious mistakes don't happen around here. & 0.53 & & & & & & & \\
\hline A17. We had patient safety problems in this unit. & 0.44 & & & & & & & \\
\hline A18. Our procedures and systems are good at preventing errors from happening. & 0.59 & & & & & & & \\
\hline C1. We are given feedback about changes put into place based on event reports. & 0.59 & & & & & & & \\
\hline C3. We are informed about errors that happen in this unit. & & -0.54 & & & & & & \\
\hline C5. In this unit, we discuss ways to prevent errors from happening again. & 0.41 & & & & & & & 0.43 \\
\hline C2. Staff will freely speak up if they see something that may negatively affect patient care. & 0.57 & & & & & & & \\
\hline C4. Staffs are afraid to ask questions when something does not seem right. & 0.48 & & & & & & & \\
\hline C6. Staffs feel free to question the decisions or actions of those with more authority. & 0.55 & & & & & & & \\
\hline A8. Staff feel like their mistakes are held against them. & & & 0.42 & & & & & \\
\hline A12. When an event is reported, it feels like the person is being written up, not the problem. & & & 0.66 & & & & & \\
\hline A16. Staff worry that mistakes they make are kept in their personnel file. & & & 0.59 & & & & & \\
\hline F4. There is good cooperation among hospital units that need to work together. & 0.66 & & & & & & & \\
\hline A2. We have enough staff to handle the workload. & 0.68 & & & & & & & \\
\hline A5. Staffs in this unit work longer hours than is best for patient care. & & -0.47 & & & 0.41 & & & \\
\hline A7. We use more agency/temporary staff than is best for patient care. & -0.41 & & & 0.43 & & & & \\
\hline A14. We work in "crisis mode" trying to do too much, too quickly. & 0.40 & & & & & & & \\
\hline
\end{tabular}

qualification level in dimensions of Overall Perception of Patient Safety and Feedback \& Communication About Errors was higher than that of physicians with a low qualification level, while in some dimension such as Teamwork Within Units, Management Support For Patient Safety, Communication Openness, Teamwork Across, Units and Non-punitive Response to Errors was lower than that of physicians with a low qualification. The results were consistent with two studies by Said B. Turkey in 2009 and 2012 [13,28].

Patient safety in health care system has gained much attention since the Institute of Medicine (IOM) reported the publication of To Err Is Human: Building a Safer Health System. As high as 44 000-98 000 of the people died from medical errors annually in US, what is alarming is the number of deaths, permanent disability and avoidable injuries that has resulted from the high incidence of medical error. Patient safety issues in developing countries are also questionable. E.g. Relevant studies in China showed that a total of 200,000 patients died from drug adverse every year, and 10\%-30\% of inpatients suffered from drug adverse reactions each year [29]. Chinese Hospital Association (CHA) estimated that adverse events affect $1.6 \sim 7.6$ million hospitalizations annually in Chinese hospitals [30]. The HSOPSC survey results in our study demonstrated that the hospitals and health care organizations in China should develop strategies to improve health quality and ensure patient safety. These strategies include: providing training and education on patient safety for health care workers in different levels (undergraduate education, 
continuing education, lectures and meetings); allocating enough staff and adequate workload; developing and fostering patient safety culture especially in the form of a non-punitive culture, creating an open communication atmosphere for reporting medical errors and speaking up when any problem arises.

\section{Reliability and validity}

Our result showed that internal consistency reliability was acceptable in China (Cronbach's $\alpha=0.84$ ), eight factors were drawn, which could explain $60 \%$ variance. The results were less satisfactory than those of the US [31]. However the results were almost similar to the study conducted in Norway [12]. Three reasons could account for this. Firstly, scale should not be translated and applied in another setting of a different cultural context directly [11,19]; secondly, culture of organization leadership, policy belief and management pattern were diverse between the US and China; thirdly, 13 original items were omitted from the report, therefore the, reliability and validity could contribute to the change.

\section{Advantages and limitations}

This is the first kind of study that was conducted in China in different cities and hospitals with different health care workers. This is different from other studies published in China that only focused on nurses or assessment only on the scale of HSPSC [19]. The results of this study may provide some evidence to help relevant Chinese decision makers develop effective strategies on improving the quality of health care to ensure patient safety. However, our study also has some limitations. Firstly, thirteen original items were deleted that might influence the framework of the patient safety culture survey. Secondly, there were very few respondents from the hospital management level, which may not reflect the whole picture of patient safety culture in China.

\section{Conclusion}

The results demonstrated that amongst the health care workers surveyed in China there was a positive attitude towards patient safety culture in their organizations. Different position, qualification and work units may have different responses for different dimensions or items. The questionnaire used in our study was acceptable according to HSPSC (version 2010).

\section{Competing interests}

The authors declared that they have no conflict of interests.

\section{Authors' contributions}

YLN and XYM contributed equally to this study. MMZ conceptualized and designed the study. YLN, CH and $\mathrm{J}, \mathrm{SH} H$ did data collection and input. XYM checked and review data. YLN performed the data analysis and XYM contributed to the interpretation of the data. MMZ and XYM contributed to and revised the manuscript critically for intellectual content. All authors read and approved the final draft.

\section{Acknowledgement}

Thanks for all the respondents who took part in this survey. Thanks Kathren Sieminski and Jinlu Xu for their help with English revising and polishing. This project was supported by the National Natural Science foundation No. 70973083.

\section{Author details}

${ }^{1}$ Chinese Evidence-based Medicine Center, West China Hospital, Sichuan University, Chengdu 610041, PR China. ${ }^{2}$ School of Public Health, Sichuan University, Chengdu, PR China. ${ }^{3}$ Department of Nursing, Yijishan Hospital, Wannan Medical College, Wuhu, PR China.

Received: 11 January 2013 Accepted: 19 June 2013

Published: 24 June 2013

\section{Reference}

1. Aspden P, Corrigan J, Wolcott J: Patient Safety, Achieving a New Standard for Care. Washington, D.C.: The National Academies Press; 2004

2. Reid PR, Compton WD, Grossman JH, Fanjiang G: Building a better delivery system. A new engineering/health care partnership. Washington, D.C.: National Academies Press; 2005:15.

3. Hughes RG, Clancy CM: Working conditions that support patient safety. J Nurs Care Qual 2005, 20(4):289-292.

4. Kohn LT, Corrigan JM, Donaldson MS: To err is human: building a safer health system. Washington D.C.: National Academy Press; 1999.

5. Schein E: Organizational Culture and Leadership San Francisco. San Francisco: Jossey-Basss; 1985.

6. Ronald GS: Developing and operationalizing a culture of safety. Chinese Hospitals 2005, 9(12):7-8.

7. Clarke S: Perceptions of organizational safety: implications for the development of safety culture. J Org Behavior 1999, 20(2):185-198.

8. Zohar D: Safety climate in industrial organizations: theoretical and applied implications. J App/ Psychol 1980, 65(1):96-102.

9. Zohar D: A group-level model of safety climate: testing the effect of group climate on microaccidents in manufacturing jobs. J App/ Psychol 2000, 85(4):587-596.

10. Chen IC, $\mathrm{Li} \mathrm{HH}$ : Measuring patient safety culture in Taiwan using the Hospital Survey on Patient Safety Culture (HSOPSC). BMC Health Serv Res 2010, 10:152-162.

11. Matsubara S, Hagihara A, Nobutomo K: Development of a patient safety climate scale in Japan. Int J Quality in Health Care 2008, 20(3):211-220.

12. Haugen AS, Søfteland E, Eide GE, Nortvedt MW, Karina Aase K, Harthug S: Patient safety in surgical environments: cross-countries comparison of psychometric properties and results of the Norwegian version of the hospital survey on patient safety. BMC Health Serv Res 2010, 10:279.

13. Bodur S, Filiz E: Validity and reliability of Turkish version of "hospital survey on patient safety culture" and perception of patient safety in public hospitals in turkey. BMC Health Serv Res 2010, 10:28

14. Smits M, Christiaans-Dingelhoff I, Wagner C, Van Der wal G, Groenewegen PP: The psychometric properties of the 'hospital survey on patient safety Culture' in Dutch hospitals. BMC Health Serv Res 2008, 8:1-9.

15. El-Jardali F, Jaafar M, Dimassi H, Jamal D, Hamdan R: The current state of patient safety culture in Lebanese hospitals: a study at baseline. Int J Qual Health Care 2010, 22:386-395.

16. Lee WC, Wung HY, Liao HH, Lo CM, Chang FL, Wang PC, Fan A, Chen HH, Yang HC, Hou SM: Hospital safety culture in Taiwan: a nationwide survey using Chinese version safety attitude questionnaire. BMC Health Serv Res 2010, 10:234.

17. Hellings J, Schrooten W, Klazinga N, Vleugels A: Challenging patient safety culture: survey results. Int J Health Care Qual Assur 2007, 20(7):620-632.

18. Agency for Healthcare Research and Quality(AHRQ): International Use of the Surveys on Patient Safety Culture.; 2012. http://www.ahrq.gov/legacy/qual/ patientsafetyculture/pscintusers.htm

19. Zhu J, Li LP, Shi MY, Lu HY, Garnick DW, Weingart SN: What constitutes patient safety culture in Chinese hospitals? Int J Qual Health Care 2012 2012:2012.

20. Hospital Survey on Patient Safety Culture: Comparative Database Report. AHRQ Publication No. 07-0025, April 2007. Rockville, MD: Agency for 
Healthcare Research and Quality; 2007. http://www.ahrq.gov/professionals/ quality-patient-safety/patientsafetyculture/hospital/2007/index.html

21. Sorra J, Famolaro T, Dyer N, Nelson D, Smith SA: Hospital Survey on Patient Safety Culture: 2012 User Comparative Database Report. Prepared by Westat, Rockville, MD, under Contract No. HHSA 290200710024C. AHRQ Publication No. 12-0017. Rockville, MD: Agency for Healthcare Research and Quality; 2012. http:/www.ahrq.gov/ professionals/quality-patient-safety/patientsafetyculture/hospital/2012/index.html

22. Grant MJ, Donaldson AE, Larsen GY: The safety culture in a children's hospital. J Nurs Care Qual 2006, 21(3):223-229.

23. Cheng B: Chinese culture and organizational leadership: From phenomenological description to theory testing. Indigenous Psychol Res Chinese Soc 2002, 22:3-48.

24. de Pablos PO: Western and Eastern views on social networks. Learning Org 2005, 12(5):436-456.

25. Johnstone MJ, Kanitsaki O: Culture, language, and patient safety: making the link. Int J Qual Health Care 2006, 18(5):383-388.

26. Triandis HC, Bontempo R, Villareal MJ, Asai M, Lucca N: Individualism and collectivism: Cross-cultural perspectives on self-ingroup relationships. J Personal Soc Psychol 1988, 54(2):323-338

27. Simpson RL: Patient and nurse safety: how information technology makes a difference. Nurs Adm Q 2005, 29(1):97-101.

28. Bodur S, Filiz E: A survey on patient safety culture in primary healthcare services in Turkey. Int J Qual Health Care 2009, 21(5):348-355.

29. The top 10 events in Chinese healthcare organization in 2005. http://www. h-ceo.com/

30. Cao RG: Medical quality and patient safety in China. Chinese Hospitals 2007, 11(11):1-4

31. Sorra JS, Dyer N: Multilevel psychometric properties of the AHRQ hospital survey on patient safety culture. BMC Health Serv Res 2010, 10:199.

doi:10.1186/1472-6963-13-228

Cite this article as: Nie et al:: Hospital survey on patient safety culture in China. BMC Health Services Research 2013 13:228.

\section{Submit your next manuscript to BioMed Central and take full advantage of:}

- Convenient online submission

- Thorough peer review

- No space constraints or color figure charges

- Immediate publication on acceptance

- Inclusion in PubMed, CAS, Scopus and Google Scholar

- Research which is freely available for redistribution 